\title{
Design of Hydraulic Control System for Press Machine and Analysis on Its Fluid Transmission Features
}

\author{
Fang Zhang \\ School of Mechatronics Engineering, Zibo Vocational Institute, Zibo 255000, China
}

Corresponding Author Email: zhfbaby@126.com

https://doi.org/10.18280/ijht.390117

Received: 5 October 2020

Accepted: 26 December 2020

\section{Keywords:}

press machine, hydraulic control system, analysis on fluid transmission features

\begin{abstract}
The stability and reliability of hydraulic control system have a direct bearing on the overall dynamic performance of the press machine. Hydromechanical analysis on the hydraulic control system is of theoretical and practical significance to improving the transmission performance and structural design of the entire press machine. From a quantitative perspective, this paper firstly analyzes the fluid transmission features of the hydraulic control system for the press machine, and presents the fluid transmission route and design drawings of the hydraulic control system. The next step is the design of the hydraulic control system. The authors specified the steps of design and calculation for the hydraulic control cylinder, and the principles for determining the power of the diesel engine. After that, experiments were carried out to verify the dynamic and static features of the designed system, and prove that our system is scientific and rational.
\end{abstract}

\section{INTRODUCTION}

The hydraulic control system is the core working component of the pressure machine. The stability and reliability of the system have a direct bearing on the overall dynamic performance of the press machine [1-3]. Hydromechanics mainly discusses the mechanical movement and equilibrium law of the liquid in the hydraulic control system, as well as the interaction pattern between hydraulic components. Hydromechanical analysis on the hydraulic control system is of theoretical and practical significance to improving the transmission performance and structural design of the entire press machine.

Raz and Vaclav [4] studied the structure, movement, and force of the hydraulic pump with fluid-heat-structure coupling features under specific working conditions, discretized the oil film feature model by finite-volume method, drawing on theories of dynamics and fluid dynamics, and simulated the liquid thickness, pressure, and temperature fields in the hydraulic pump on MATLAB, revealing the change law of these fields in a cycle.

Currently, there are few studies on the operating mechanism of modern hydraulic systems under extremely high or low temperatures [5-9]. From the perspective of fluid mechanics, Coetzer [10] simulated the fluid flow in the orifices and gaps of the hydraulic system, and constructed the corresponding experimental device; then, Coetzer conducted structural design of the mechanical platform and drive equipment for the system, and designed the electrical, measurement and control systems in terms of component selection, circuit design, and drive control; finally, Coetzer completed test bench construction, process integration, system debugging and sensor calibration.

If the fluid has a low lubricity, the parts of the hydraulic transmission system will easily fail due to friction damage [1115]. To avoid the failure, Malygin et al. [16] replaced the traditional hydraulic medium to improve the lubrication conditions of the system components, selected the magnetic fluid that meets the viscosity requirements based on sedimentation stability and viscosity features, and demonstrated the superior lubricity of magnetic fluid through comparative experiments against anti-wear hydraulic oil.

The traditional press machine cannot meet the strict requirements on the deep drawing of thin sheets. There is a high market demand for press machines supporting userdefined kinematic indices like stroke and speed [17-21]. Huang et al. [22] provided an overall design plan for the hydraulic control system of computer numerically controlled (CNC) servo press machine, checked the pressure and heat losses of the system after determining the components and parts, and constructed an Adams simulation model on the stability, observability, and controllability of the system.

In metal sheet compression molding, the preparation of new-generation high-performance materials put forward stricter requirements on the performance design of the hydraulic control system for the mechanical press machine. According to the process requirements on advanced press machine, Malygin et al. [23] designed and analyzed the hydraulic and electrical control programs for each action of the mechanical press machine, and developed detailed wiring diagram, control principle diagram, and design diagram of automatic protection and control system. Monn et al. [24] completed the detailed design of the hydraulic control system for the press machine of compressed garbage; after selecting the components and parts, Monn simulated and modeled the drive system, and analyzed the reliability of the main propulsion circuit; the design of the main propulsion control, electronic control, hydraulic circuit, and internal pipes was proved reasonable and correct. From both static and dynamic aspects, Kramer and Rexroth [25] conducted feature analysis and simulation modeling of the main circuits of the hydraulic system for the brick press machine, namely, moving beam 
descending circuit, pressing circuit, and ejection circuit, examined the physical features like displacement, pressure, and flow, and presented an effective scheme to reduce the water hammer in the system.

To sum up, the existing studies at home and abroad mainly focus on the theoretical analysis, numerical simulation, and experimental research on the hydraulic control system of press machines. The hydraulic fluid transmission technology has reached an advanced level in foreign countries. Chinese scholars have also achieved quite a few results in this respect. However, the fluid transmission features are mostly obtained based on lots of assumptions and simplifications, the empirical system design faces many limitations, and no one has yet applied the analysis results of fluid transmission features to the design of hydraulic control system for press machines.

To overcome the above defects, this paper firstly analyzes the fluid transmission features of the hydraulic control system for the press machine, and presents the fluid transmission route and design drawings of the hydraulic control system. Next, the authors specified the steps of design and calculation for the hydraulic control cylinder, and the principles for determining the power of the diesel engine. Finally, experiments were carried out to verify the dynamic and static features of the designed system, and prove that our system is scientific and rational.

\section{TRANSMISSION FEATURE ANALYSIS}

According to the different functions of the confluence or shunt power for the planetary gearset, the transmission mode of the hydraulic control system for the press machine can be divided into the output shunt type (where the planetary gearset lies at the output end of the system) and the input shunt type (where the planetary gearset lies at the input end of the system). This paper chooses to discuss the fluid transmission features of the output shunt type system.

Figure 1 shows the structure of the output shunt type hydraulic control system. Using the variable pump-constant drive motor circuit, the hydraulic closed circuit of the press machine outputs a constant torque; the relative change rate of the displacement of the variable pump is proportional to the speed of the drive motor in the circuit. The speed of the drive motor can be regulated by adjusting the displacement of the variable pump. Thus, this hydraulic control system is an ideal choice for industrial and agricultural mechanical press machines.

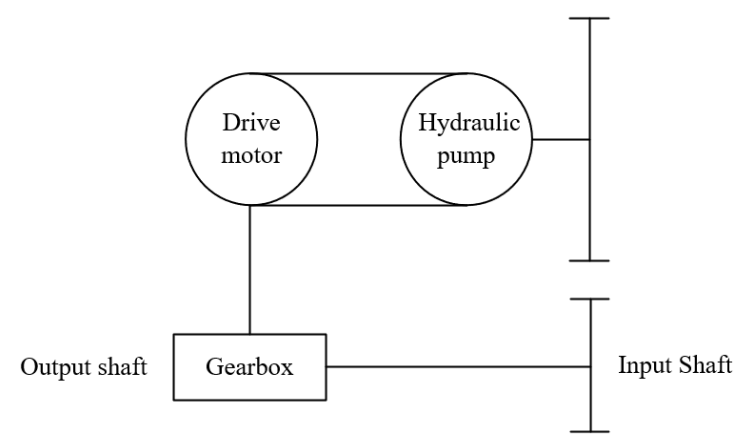

Figure 1. Structure of the output shunt type hydraulic control system

The fluid displacement of each link in the system is multiplied with the speed of the drive motor. Then, the output flow of the hydraulic pump $w_{H P O}$ equals the input flow of the drive motor $w_{H M I}$ :

$$
w_{H P O}=w_{H M I}
$$

Let $P_{H P D}$ and $m_{H P S}$ be the displacement and speed of the hydraulic pump, respectively. Then, $w_{H P O}$ can be calculated by:

$$
w_{H M I}=p_{H P D} \cdot m_{H P D}
$$

Let $P_{H M D}$ and $m_{H M O}$ be the displacement and speed of the drive motor, respectively. Then, $w_{H M I}$ can be calculated by:

$$
w_{H M I}=P_{H M D} m_{H M O}
$$

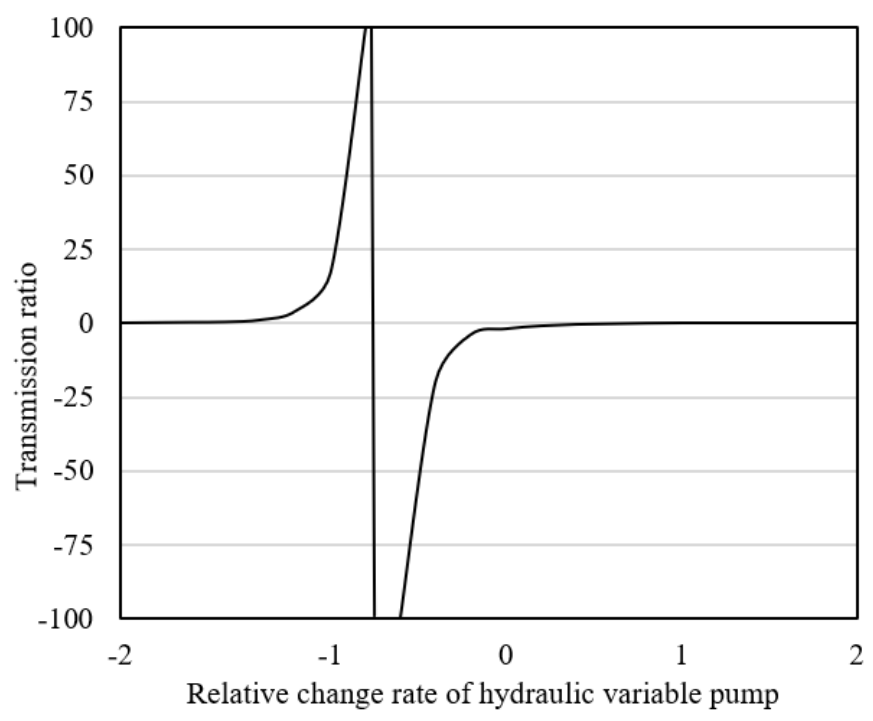

Figure 2. Output speed curve

Figure 2 shows the output speed curve of the output shunt type system. Let $P_{H P D-\max }$ and $\tau$ be the maximum displacement and relative displacement change rate of the hydraulic pump, respectively. Then, $P_{H P D}$ can be calculated by:

$$
P_{H P D}=P_{H P D-\max } \tau
$$

Since $P_{H P D-\max } \times m_{H P S \times \tau}=P_{H M D} \times m_{H M O}$ and $P_{H P D-\max }=P_{H M D}$ :

$$
m_{H M O}=m_{H P S} \tau
$$

Formula (5) shows that $m_{H M O}$ is proportional to $\tau$. Under operating conditions, general industrial and agricultural mechanical presses have a limited range of force. The single planetary gearset is sufficient to meet the working requirements. Let $m_{S W}, m_{R T}$, and $m_{i}$ be the speeds of the sun gear, ring gear, and planetary carrier, respectively; $l$ be the characteristic parameter of the planetary gearset. Then, the kinematics equation of the planetary gearset can be expressed as:

$$
m_{S W}+l m_{R T}-(1+l) m_{i}=0
$$

Let $W_{S W}, W_{R T}$, and $W_{i}$ be the input or output powers of the sun gear, ring gear, and planetary carrier, respectively. Then, the input and output powers of the planetary gearset satisfy: 


$$
W_{S W}+W_{R T}+W_{i}=0
$$

Let $T_{S W}, T_{R T}$, and $T_{i}$ be the torques of the sun gear, ring gear, and planetary carrier, respectively. Then, the torque feature of the planetary gearset can be expressed by:

$$
T_{S W}: T_{R T}: T_{i}=1: l:-(1+l)
$$

Figures 3 and 4 are the schematic diagrams of the fluid transmission route of the hydraulic control system for the press machine, and the detailed design drawings of 6 different transmission routes, respectively. The following is an analysis on the features of the route(s). Let $m_{E T}$ be the speed of the input shaft. Then, we have:

$$
m_{H P S}=m_{E T}
$$

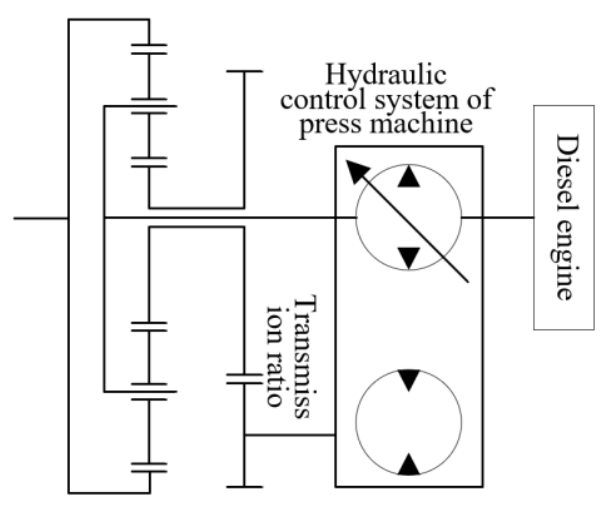

(a)

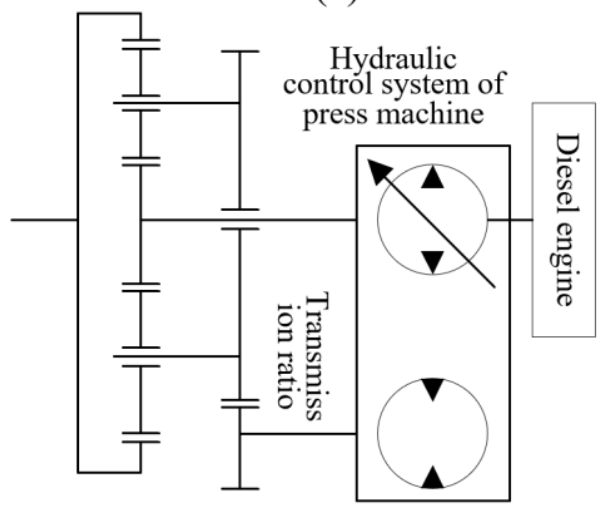

(c)

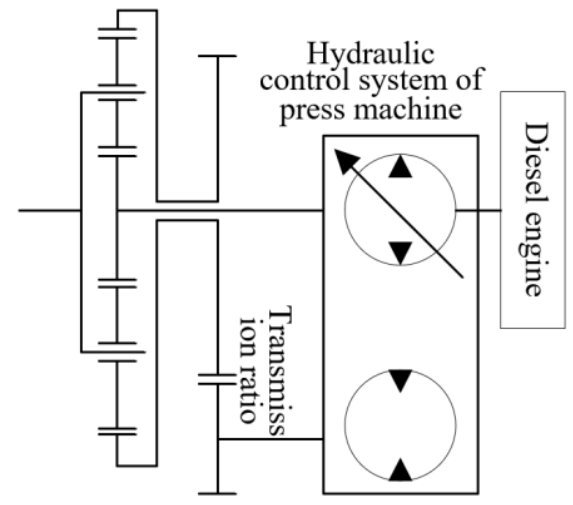

(e)

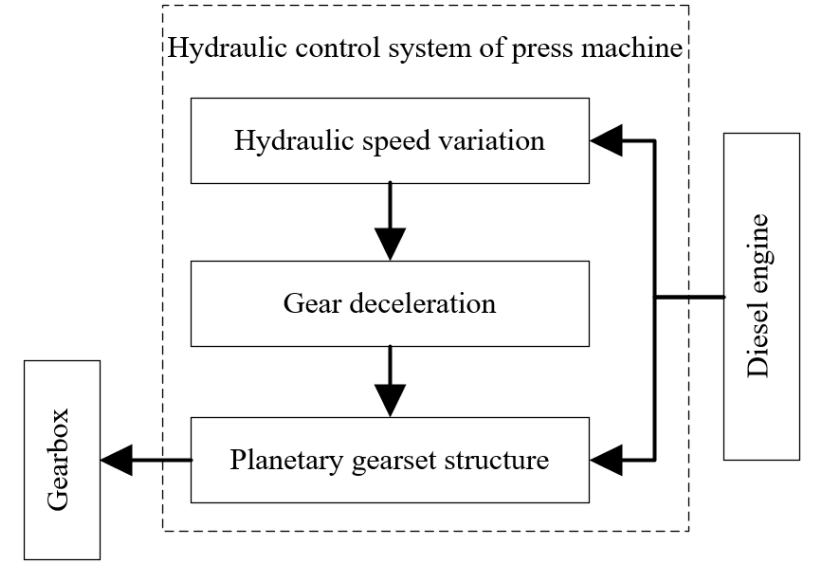

Figure 3. Fluid transmission route of the hydraulic control system for the press machine

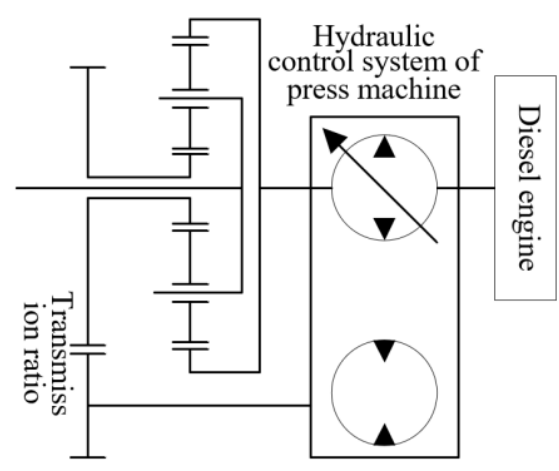

(b)

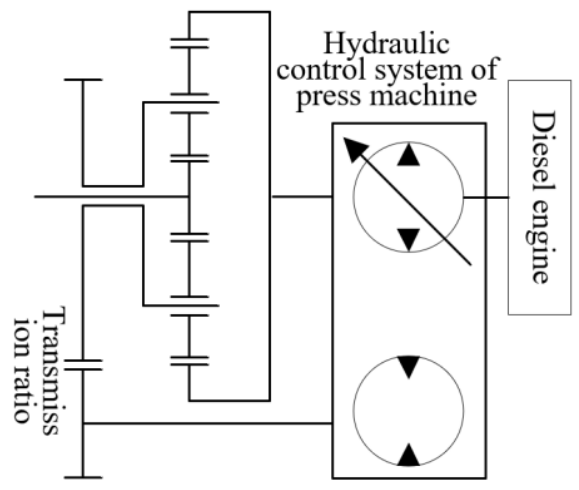

(d)

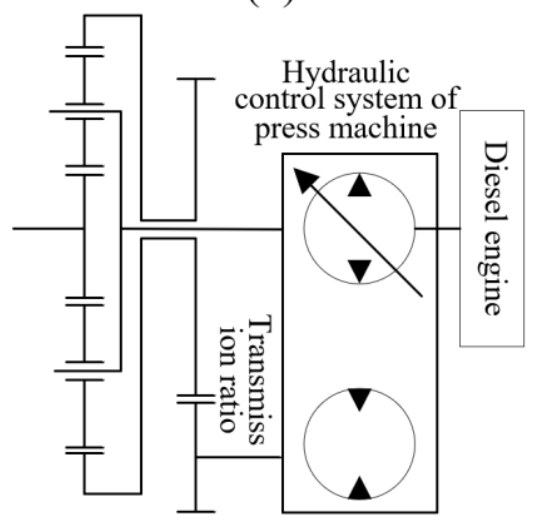

(f)

Figure 4. Design drawings of the hydraulic control system 
Combining formulas (8) and (9):

$$
T_{S W}=\frac{T_{R T}}{l}=\frac{T_{i}}{-(1+l)}
$$

Let $\lambda_{H R}$ be the shunt ratio of hydraulic power; $W_{H R}$ be the power of hydraulic circuit; $W_{C S}$ be the output power of the transmission system. Then, the shunt ratio of hydraulic power can be expressed as:

$$
\lambda_{H R}=-\frac{W_{H R}}{W_{C S}}
$$

Formula (11) shows the power transmitted from the hydraulic circuit to the planetary gearset depends on the negative ratio of $W_{H R}$ to $W_{C S}$. If the input of the hydraulic part is the sun gear, the input of the mechanical part is the planetary carrier, and the total output of the system is the ring gear, the fluid transmission feature of the hydraulic control system for the press machine can be deduced as follows.

The relationship between $m_{H M O}$ and $m_{S W}$ can be described by:

$$
m_{S W}=\frac{m_{H M O}}{j}
$$

where, $j$ is the transmission ratio of reduction gear. The relationship between $m_{H P S}$ and $m_{i}$ can be expressed by:

$$
m_{i}=m_{H P S}
$$

Let $m_{C S}$ be the output speed. Then, the relationship between $m_{i}$ and $m_{C S}$ can be expressed as:

$$
m_{R T}=m_{C S}
$$

Combining formulas (13) and (14):

$$
m_{i}=m_{E T}
$$

From formula (15), $m_{S W}$ can be described by:

$$
m_{S W}=\frac{m_{H M O}}{j}=\frac{m_{H P S} \tau}{j}=\frac{m_{E T} \tau}{j}
$$

Then, $m_{R T}$ and $m_{C S}$ can be respectively obtained by:

$$
\begin{gathered}
m_{R T}=\frac{(l+1) m_{i}-m_{j}}{l}=\frac{(l+1) m_{i}-\frac{1}{j} m_{E T} \tau}{l} \\
=\left(\frac{(l+1)-\frac{\tau}{j}}{l}\right) m_{E T} \\
m_{C S}=m_{R T}=\left(\frac{(l+1)-\frac{\tau}{j}}{l}\right) m_{E T}
\end{gathered}
$$

Next is an analysis on the torque features of the hydraulic control system for the press machine. According to plan 1, the relationship between input torque $T_{H M O}$ and $T_{S W}$ can be described by:

$$
T_{S W}=j T_{H M O}
$$

The relationship between $T_{R T}$ and output torque $T_{C S}$ can be described by:

$$
T_{C S}=T_{R T}
$$

Combining formula (19) with formula (8):

$$
T_{S W}=\frac{T_{R T}}{l}
$$

Combining formula (20) with formula (8):

$$
T_{C S}=l j T_{H M O}
$$

Under the same condition, the power shunt ratio of the hydraulic control system can be expressed as:

$$
\lambda_{H R}=-\frac{W_{H R}}{W_{C S}}=-\frac{T_{S W} m_{S W}}{T_{R T} m_{R T}}
$$

where, the ratio of $T_{S W}$ to $T_{R T}$ can be calculated by:

$$
\frac{T_{S W}}{T_{R T}}=\frac{1}{l}
$$

where, the ratio of $m_{S W}$ to $m_{R T}$ can be calculated by:

$$
\frac{m_{S W}}{m_{R T}}=\frac{l \tau}{(l+1) j-\tau}
$$

Formula (23) can be updated into:

$$
\lambda_{H R}=-\frac{W_{S W}}{W_{C S}}=\frac{\tau}{\tau-(l+1) j}
$$

\section{SYSTEM DESIGN AND CALCULATION}

\subsection{Design and calculation of hydraulic control cylinder}

The hydraulic control cylinder is the core component of the hydraulic control system in industrial and agricultural mechanical press machines. The former undertakes the task of direct compression molding, and provides the main space for fluid transmission. Table 1 presents the outer diameters of piston rods in oil cylinder and air cylinder. Based on the measured results on sample equipment, the following parameters of the hydraulic control cylinder can be determined: the piston rod diameter $f$, working pressure $V$ of hydraulic control cylinder, and maximum stroke $K$ of hydraulic control cylinder. Table 2 presents the working pressure of the oil cylinder under different piston rod diameters. According to the general correspondence between the working pressure of the 
oil cylinder and the diameter of the piston rod, the piston rod diameter $F$ of the designed oil cylinder can be selected according to the working pressure:

$$
F=\frac{f}{0.7}
$$

Table 1. Outer diameters of piston rods in oil cylinder and air cylinder

\begin{tabular}{cccccc}
\hline Oil cylinder & 8 & 40 & 125 & 280 & 320 \\
\hline & 10 & 60 & 150 & 330 & 440 \\
& 15 & 65 & 163 & 357 & 520 \\
Air cylinder piston rod & 20 & 84 & 174 & 386 & 580 \\
& 25 & 96 & 186 & 422 & $/$ \\
& 30 & 112 & 197 & 453 & $/$ \\
& 35 & 126 & 224 & $/$ & $/$ \\
\hline
\end{tabular}

Table 2. Working pressure of the oil cylinder under different piston rod diameters

\begin{tabular}{cccc}
\hline Diameter & $\leq 6$ & $6 \sim 8$ & $\geq 8$ \\
\hline Working pressure & $(0.5 \sim 0.64) F$ & $(0.64 \sim 0.8) F$ & $0.8 F$ \\
\hline$f$ &
\end{tabular}

Then, the piston width $E$ can be calculated by:

$$
E=(0.5 \sim 1.1) \times F
$$

The length $C$ of the sliding surface of the guide sleeve (Figure 5) can be calculated by:

$$
C=(0.6 \sim 1.0) \times f
$$

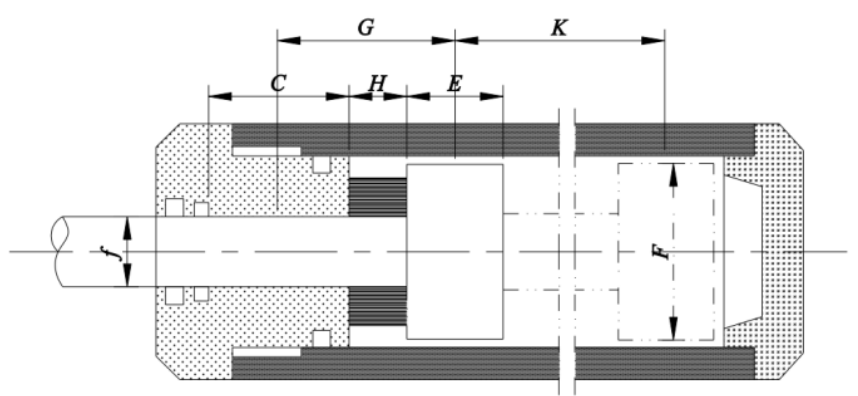

Figure 5. Length of the sliding surface of the guide sleeve

When the piston rod is fully extended, if the distance from the midpoint of the piston bearing surface to the midpoint of the sliding surface of the guide sleeve is too small, the initial deflection of the hydraulic control cylinder will increase, undermining the stability of the cylinder. Therefore, the guide length $G$ must be minimized in the design. Let $K$ be the maximum stroke of hydraulic control cylinder, and $F$ be the inner diameter of the oil cylinder. Then, $G$ must satisfy the following inequality:

$$
G \geq \frac{K}{20}+\frac{F}{2}
$$

A spacer can be installed between the guide sleeve and the piston to minimize $G$. The length of the spacer can be calculated by:

$$
S=G-(C+E) / 2
$$

Let $\xi$ be the wall thickness of hydraulic control cylinder. The diameter of piston $\operatorname{rod} f$ and $\xi$ must pass strength check before being applied in high-pressure press machines. If the $F / \xi$ is greater than $10 \mathrm{~mm}$, the wall is thick; if it is smaller than $10 \mathrm{~mm}$, the wall is thin:

$$
F / \xi<10 \text { or } F / \xi>10
$$

Let $V_{b}$ and $\mu$ be the test pressure of the cylinder and allowable stress of cylinder material, respectively. If the hydraulic control cylinder has a thick wall, then $\xi$ can be checked by:

$$
\xi \geq \frac{F}{2} \sqrt{\frac{[\mu]+0.4 V_{b}}{[\mu]-1.3 V_{b}}-1}
$$

Let $U$ be the force on piston rod. Then, $f$ can be checked by:

$$
f \geq \sqrt{\frac{4 U}{\pi[\mu]}}
$$

Let $f_{c}$ be bolt diameter. During the system operation, the set bolt on the cover of hydraulic control cylinder is subject to both torsion stress and tensile stress. Let $W$ be the load of the cylinder; $r$ be the number of set bolts; $v$ be the thread tightening coefficient. Then, $f_{c}$ can be checked by:

$$
f_{c} \geq \sqrt{\frac{5.2 l U}{\pi r[\mu]}}
$$

Let $L$ be the system leakage coefficient, and $\sum F L_{P O-\max }$ be the larger flow between oil cylinder and drive motor. Tables 3 and 4 present the parameters of the drive motor and hydraulic pump, respectively. Throughout the pressing process, hydraulic control cylinder and hydraulic drive motor do not work at the same time. The output flow of the hydraulic pump can be described as:

$$
F L_{P O} \geq L \sum F L_{P O-\max }
$$

Table 3. Parameters of hydraulic drive motor

\begin{tabular}{ccccc}
\hline Model & $q_{\max }$ & Speed $n$ & $P_{\max }$ & $T_{\max }$ \\
\hline 440 & 126 & 300 & 250 & 1,080 \\
\hline
\end{tabular}

Table 4. Parameters of hydraulic pump

\begin{tabular}{ccccc}
\hline $\begin{array}{c}\text { Rated } \\
\text { pressure }\end{array}$ & $\begin{array}{c}\text { Maximum } \\
\text { pressure }\end{array}$ & Flow & $\begin{array}{c}\text { Maximum } \\
\text { speed }\end{array}$ & $\begin{array}{c}\text { Input } \\
\text { power }\end{array}$ \\
\hline 25.76 & 28.21 & 128.35 & 2,600 & 50 \\
\hline
\end{tabular}

Let $P R_{1}$ be the maximum working pressure of hydraulic control cylinder or hydraulic drive motor, and $\sum \Delta v$ be the total loss on the pipes between hydraulic pump and hydraulic control cylinder or hydraulic drive motor. Then, the maximum working pressure of hydraulic pump can be expressed as:

$$
P R_{O H} \geq P R_{1}+\sum \Delta v
$$




\subsection{Determining the power of diesel engine}

For a hydraulic pump driven by a diesel engine, the inputs are torque and speed, and the outputs are fluid flow and pressure. Energy loss is inevitable in the conversion process of fluid transmission energy. Thus, the output power of the system is smaller than the input power. The output-input power ratio is the total efficiency of the system $\omega$. Let $P R_{M O H}$ and $P R_{H P O}$ be the maximum working pressure and maximum flow of hydraulic pump, respectively. Then, the driving power of the diesel engine can be calculated by:

$$
P R=\frac{P R_{O H} w_{P O}}{\omega}
$$

Based on the driving power calculated by formula (38), the diesel engine can be selected according to the power loss of the conversion process and the power requirements of the auxiliary equipment of the hydraulic control.

\section{EXPERIMENTS AND RESULTS ANALYSIS}

During the operation of the hydraulic control system for the press machine, the design parameters and input speed were fixed to analyze the static features of the system. Figure 6 shows the variation in the transmission ratio with the relative change rate of pump displacement. It can be seen that, the system output speed changed linearly with $\tau$. Thus, the output speed of the fluid transmission system can be regulated by changing the $\tau$ value, giving a suitable force range of the press machine. Because the linear increase or decrease directly affects the operating direction of the variable pump, it can be judged that plans 4 and 6 have relatively high sensitivity and wide range of speed adjustment; plans 1, 2, 3, and 5 have relatively low sensitivity and narrow width.

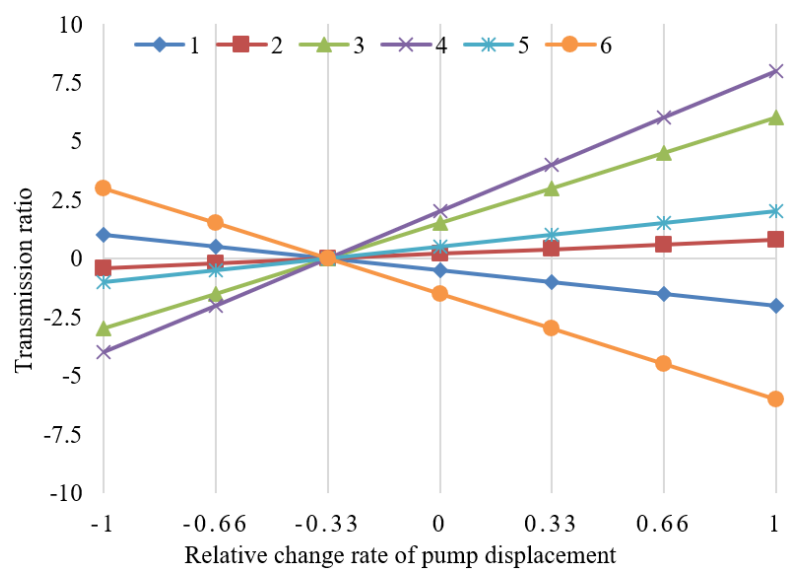

Figure 6. Variation in the transmission ratio with the relative change rate of pump displacement

Figure 7(a) shows the dynamic features of the system under different pump displacement adjustment rates, and Figure 7(b) displays the dynamic features of the system under different load torques. It can be seen that, from 0 to $25 \mathrm{~s}$, the relative change rate of hydraulic pump displacement exhibited a linear growth from -0.8 to 0.8 ; from 25 to $38 \mathrm{~s}$, the relative change rate linearly declined from 0.8 to -0.8 ; from 38 to $46 \mathrm{~s}$, the rate changed from -0.8 to -0.2 ; from 46 to $50 \mathrm{~s}$, the rate changed from -0.2 to -0.8 . During the period of $25-50 \mathrm{~s}$, the system load torque changed to $50 \mathrm{~N} \cdot \mathrm{m}$.
The on-off valve and logic valve, the oil cylinder and the oil pump, and the accumulator were treated as three subsystems. Then, MATLAB simulation was conducted to analyze the fluid transmission features of the piston in the upward and downward strokes. Figure 8 records the simulated curves of downward displacement, downward speed, upper and lower compartment pressures, accumulator flow, and accumulator pressure during the upward stroke of the piston. It can be seen that, the piston descended rapidly at the beginning. With the elapse of time and increase of displacement, the accumulator saw a gradual decline in pressure and flow. The pressure in the upper and lower compartments of the oil cylinder continued to decrease, and resulted in an inflection point at about $4 \mathrm{~m}$. The inflection point appears as the hydraulic pump changes from oil filling state to oil discharging state.

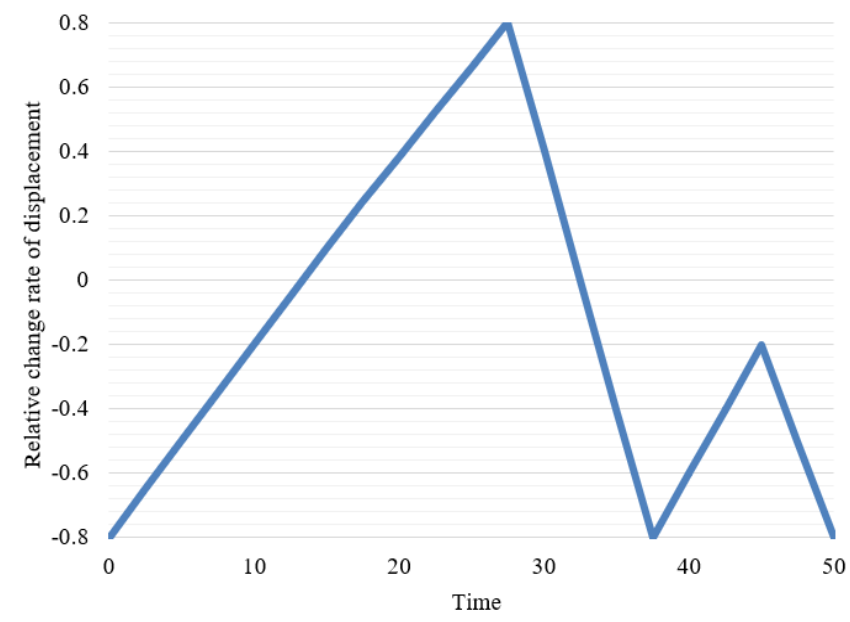

(a)

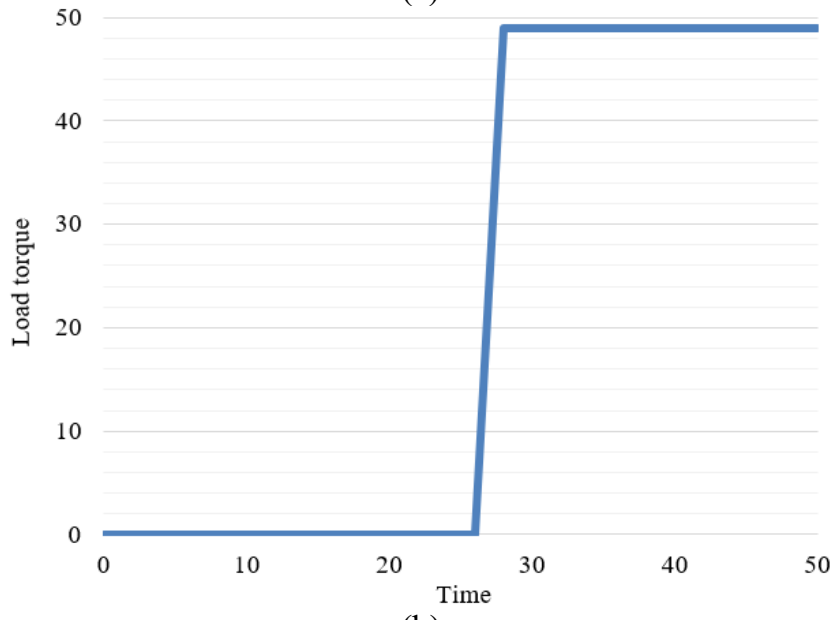

(b)

Figure 7. Variation of input parameters

Figure 9 records the simulated curves of upward displacement, upward speed, upper and lower compartment pressures, accumulator flow, and accumulator pressure, during the downward stroke of the piston. The upward speed of the piston was slow at the beginning, and quickly tended to stable. The upper and lower chambers of the oil cylinder had a small pressure. During the upward stroke, the accumulator was first filled by the hydraulic pump until it was fully filled with oil. Only in this case, was the liquid oil supplied to the lower chamber of the oil cylinder, serving to drive the upward motion of the piston. The test results agree with the actual situation, reflecting the rationality of our design for the hydraulic control system of the press machine. 


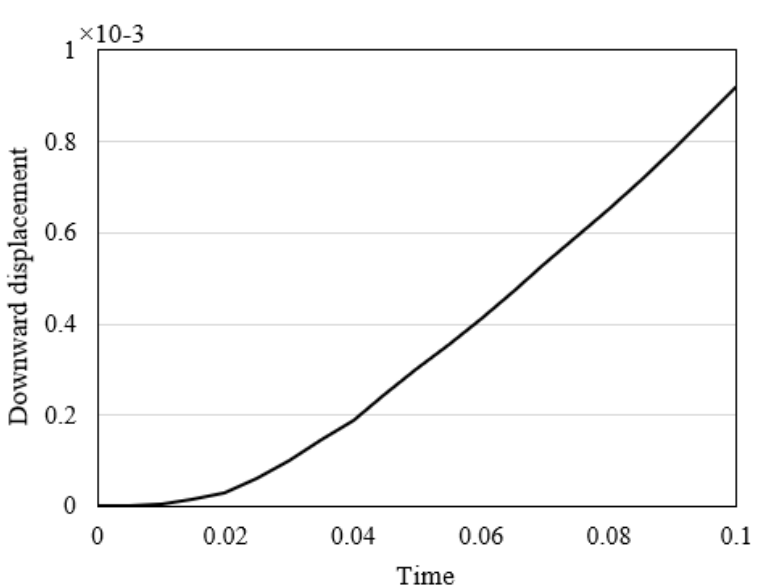

(a)

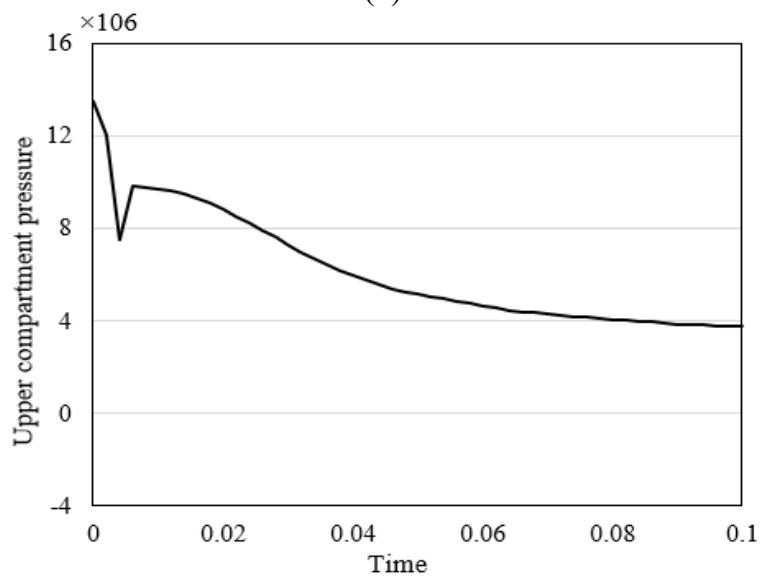

(c)

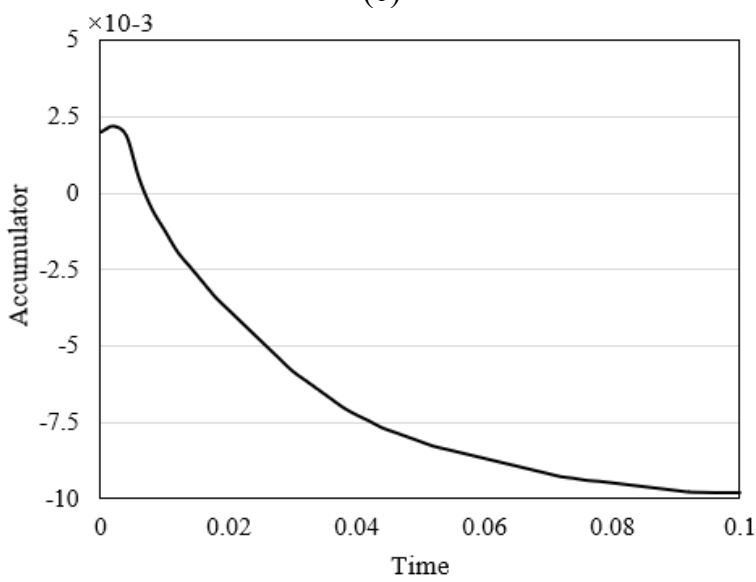

(e)

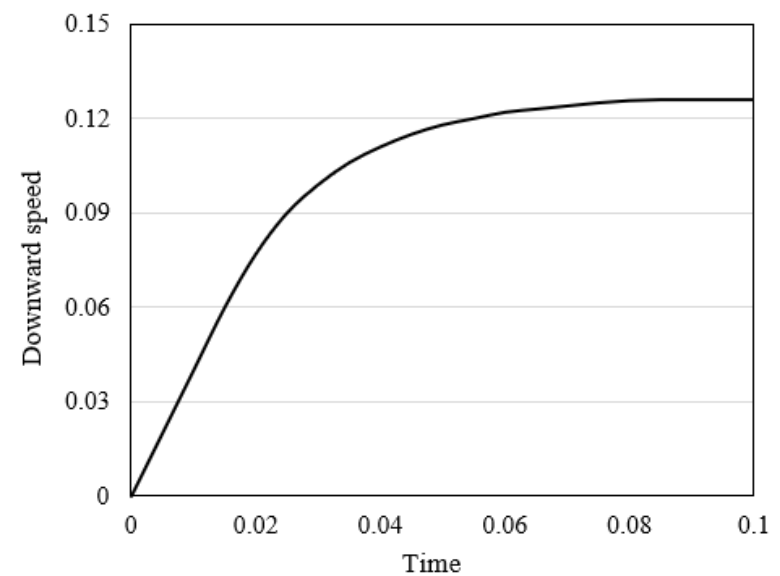

(b)

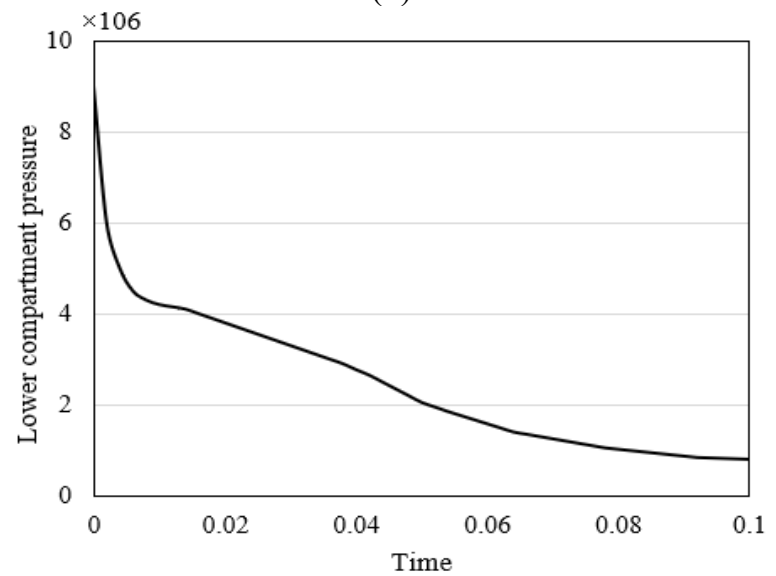

(d)

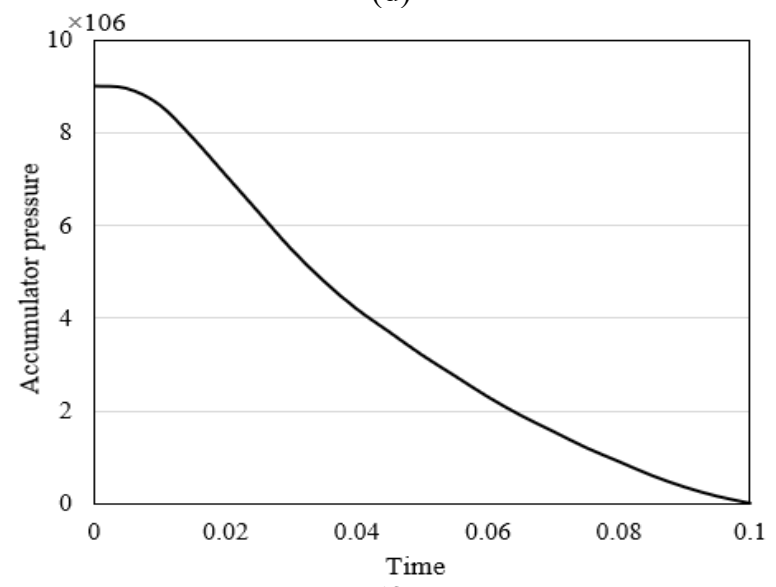

(f)

Figure 8. Simulation curves in the downward stroke

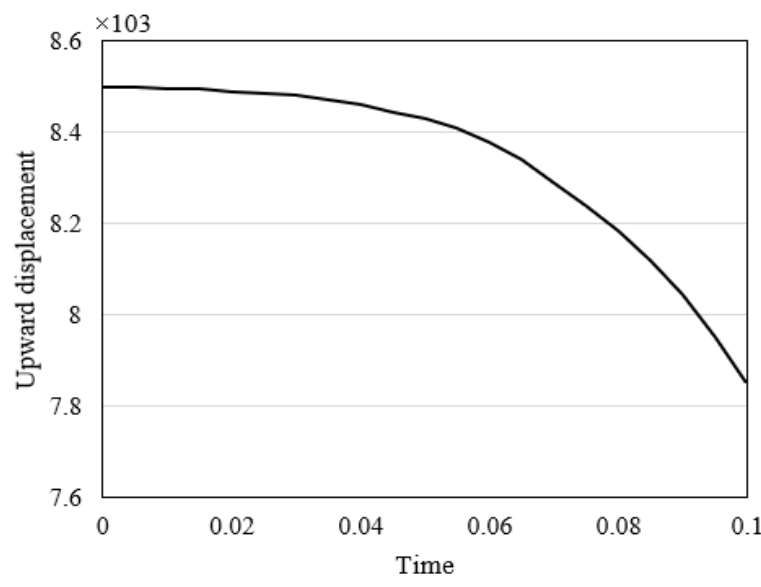

(a)

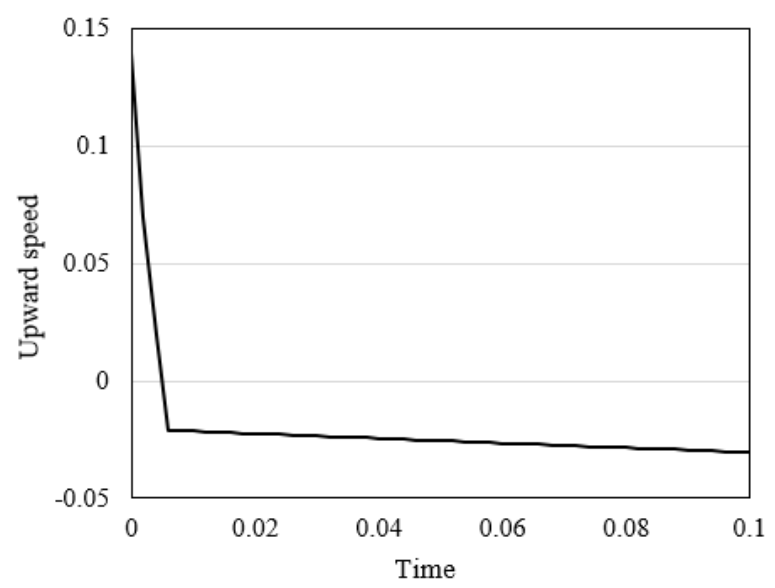

(b) 


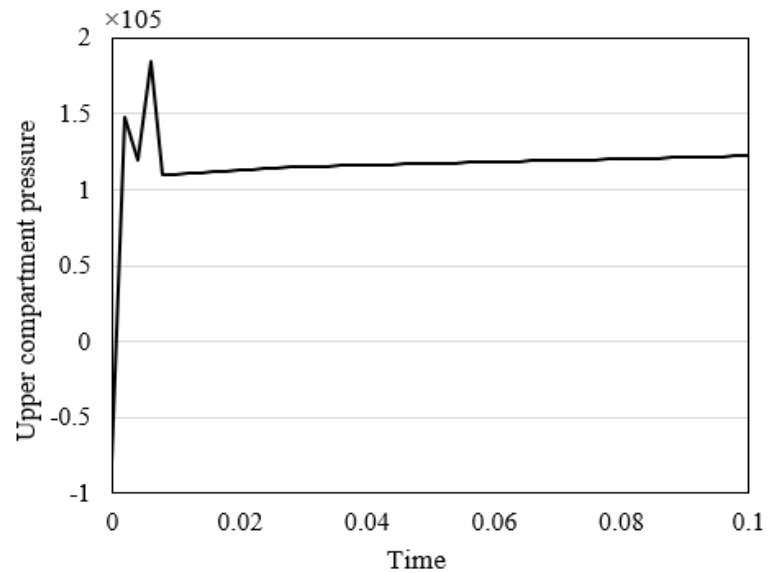

(c)

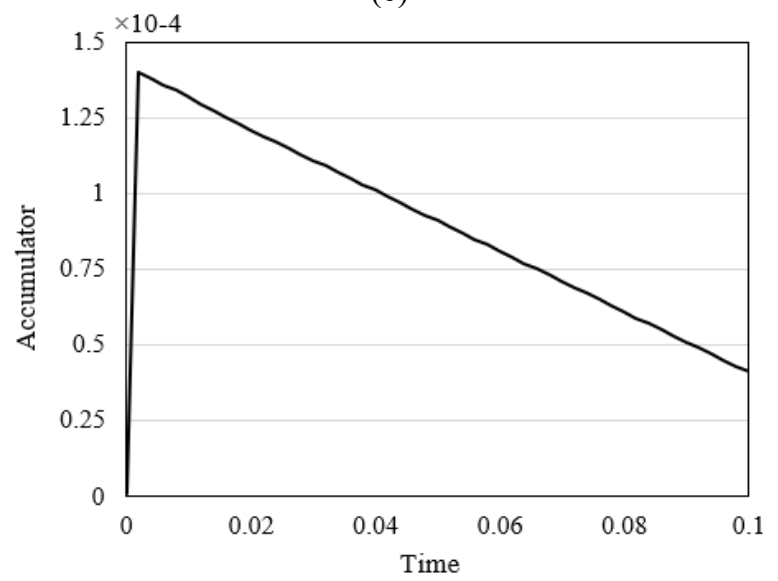

(e)

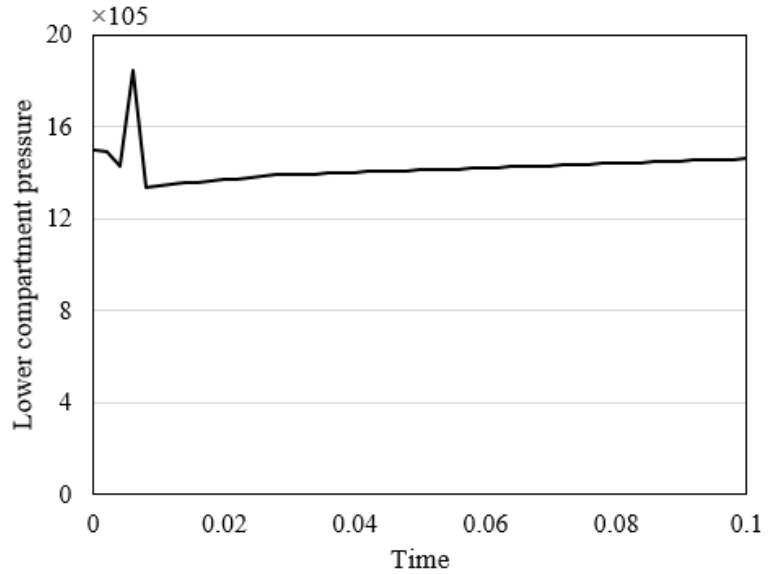

(d)

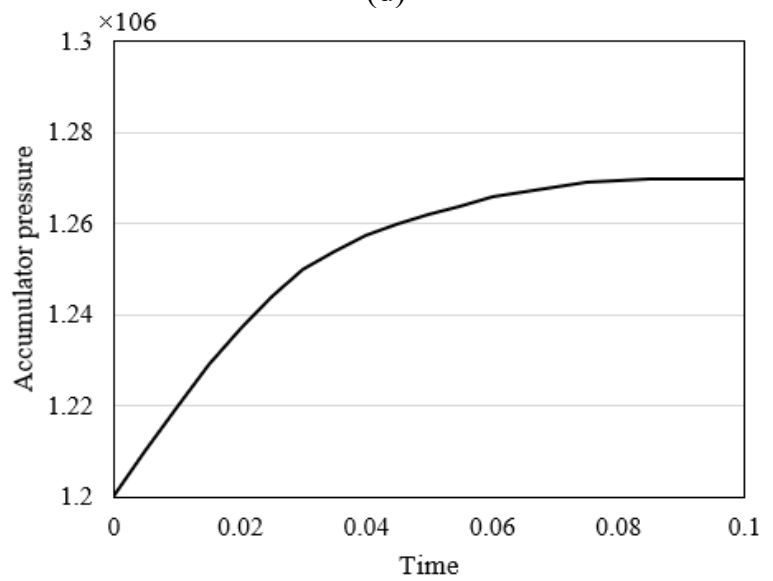

(f)

Figure 9. Simulation curves in the upward stroke

\section{CONCLUSIONS}

This paper mainly pursues the reasonable design of the hydraulic control system for press machines, and analyzes the fluid transmission features. From the quantitative angle, the fluid transmission features of the hydraulic control system were examined for press machines, and the fluid transmission route and design drawings were prepared for the hydraulic control system. Then, design flow of the hydraulic control system was described, including how to design the hydraulic control cylinder and the selection of diesel engine power. After that, several experiments were carried out to observe the variation of transmission ratio with the relative change rate of pump displacement, as well as the dynamic features of the system under different pump displacement adjustment rates and load torques. The dynamic and static features of the designed system were also analyzed. Through the simulation of the upward/downward stroke of the piston, the operating results of the designed model were proved consistent with the actual situation, reflecting the scientific nature and rationality of the proposed system.

\section{REFERENCES}

[1] Yan, X., Chen, B. (2021). Analysis of a novel energyefficient system with a bidirectional supercharger for forging hydraulic press. Journal of Cleaner Production, 286:

125520.
[2] Karpushkin, S.V., Mokrozub, V.G., Glebov, A.O., Karpov, S.V. (2021). Method for Determining the Parameters of Heating Systems for Hydraulic Presses. Chemical and Petroleum Engineering, 56(9): 744-754. https://doi.org/10.1007/s10556-021-00837-9

[3] Kramer, M., Binversie, A. (2020). Hydraulics upgrade provides notable benefits for aluminum extrusion press. Light Metal Age, 78(6): 22-23.

[4] Raz, K., Vaclav, K. (2014). Using of a hydraulic press in production and manufacturing of large rings. Procedia Engineering, 69: 1064-1069. https://doi.org/10.1016/j.proeng.2014.03.091

[5] Huang, Z., Wu, N., Chen, J. (2013). Modal analysis of $32.8 \mathrm{mn}$ energy-saving automatic hydraulic press.Energy Education Science and Technology, 31(1): 453-456.

[6] Li, J., Wang, Y., Wang, X., Shao, J., Han, G., Wu, B. (2013). Study of Electro-Hydraulic Force Servo System Based on Flow Press Servo-Valve and Fussy Intelligent Control Strategy. Journal of Computational and Theoretical Nanoscience, 10(12): 2955-2960. https://doi.org/10.1166/jctn.2013.3308

[7] Pan, Q., Huang, M.H., Li, Y.B. (2013). Modeling and identification of friction behaviors of hydraulic forging press machine. Applied Mechanics and Materials, 328: $77-83$. https://doi.org/10.4028/www.scientific.net/AMM.328.7 7

[8] Krot, P.V., Zimroz, R. (2020). Failure analysis and modernization of high-pressure hydraulic press for drilling tubes testing. Engineering Failure Analysis, 117: 
104772.

https://doi.org/10.1016/j.engfailanal.2020.104772

[9] Pan, Q., Li, Y., Huang, M., Zhao, Z., Ma, P., Ma, J. (2019). Estimation of dynamic behaviors of hydraulic forging press machine in slow-motion manufacturing process. Nonlinear Dynamics, 96(1): 339-362. https://doi.org/10.1007/s11071-019-04793-1

[10] Coetzer, G. (2019). Compaction tests on coking coals. Part 1: Laboratory-scale compaction with a 4-ton hydraulic press. Journal of the Southern African Institute of Mining and Metallurgy, 119(4): 403-411. http://dx.doi.org/10.17159/2411-9717/17/070/2019

[11] Aravind, U., Uday, C., Venugopal, P. (2019). Modified fine blanking of cam-shaped profile using a doubleaction hydraulic press. Materials and Manufacturing Processes, 34(6): 670-680. https://doi.org/10.1080/10426914.2019.1566614

[12] Basiouny, M.A. (2018). Development and performance evaluation of a hydraulic press for animal feed blocks formation. AMA, Agricultural Mechanization in Asia, Africa and Latin America, 49(1): 11-21. https://doi.org/10.21608/jssae.2015.42169

[13] Stishov, S.M. (2019). A small laboratory hydraulic press with a force of 20 tons. Instruments and Experimental Techniques, 62(5):

708-709. https://doi.org/10.1134/S0020441219040213

[14] Raz, K., Kubec, V., Cechura, M. (2015). Dynamic behavior of the hydraulic press for free forging. Procedia Engineering, 100: 885-890. https://doi.org/10.1016/j.proeng.2015.01.445

[15] Wu. A., Jia, C. (2013). Novel control scheme for multi cylinder hydraulic press. Journal of Huazhong University of Science and Technology (Natural Science Edition), 41(9): 42-47.

[16] Malygin, E., Mokrozub, V., Nemtinov, V. (2017). An information model of a hydraulic press and its representation in the automated system. In MATEC Web of Conferences, 129: 01009. https://doi.org/10.1051/matecconf/201712901009

[17] Cristofolini, I., Pilla, M., Belluzzi, D., Pederzini, G., Crocetti, M., Molinari, A. (2013). Influence of the scatter of sintered height on the precision of parts sized by a hydraulic press. European Congress and Exhibition on Powder Metallurgy. European PM Conference Proceedings.

[18] Hsieh, C.T., Lai, C.P. (2019). Nonlinear dynamic analysis and control of a hydraulic press electrohydraulic servo system. Journal of Low Frequency Noise, Vibration and Active Control, 38(3-4): 1594-1606. https://doi.org/10.1177/1461348418813021

[19] Fallahiarezoodar, A., Gupta, T., Goertemiller, C., Altan, T. (2019). Residual stresses and springback reduction in U-channel drawing of A15182-O by using a servo press and a servo hydraulic cushion. Production Engineering, 13(2): 219-226. https://doi.org/10.1007/s11740-01900878-3

[20] Thomas, A.T., Parameshwaran, R., Kumar, R.D., Mohanraja, S., Harishwaran, M. (2014). An Investigation on Modelling and Controller design of a Hydraulic press. IFAC Proceedings Volumes, 47(1): 719-725. https://doi.org/10.3182/20140313-3-IN3024.00146

[21] Coetzer, G. (2019). Compaction tests on coking coals. Part 2: Pilot-plant-scale compaction with a 60-ton hydraulic press. Journal of the Southern African Institute of Mining and Metallurgy, 119(4): 413-419. http://dx.doi.org/10.17159/2411-9717/17/071/2019

[22] Huang, H., Jin, R., Li, L., Liu, Z. (2018). Improving the energy efficiency of a hydraulic press via variable-speed variable-displacement pump unit. Journal of Dynamic Systems, Measurement, and Control, 140(11): 111006. https://doi.org/10.1115/1.4040325

[23] Malygin, E.N., Karpushkin, S.V., Glebov, A.O., Karpov, S.V. (2017). Vulcanizing hydraulic press heating system for tempering metal and alloy objects. Chemical and Petroleum Engineering, 53(5): 369-377. https://doi.org/10.1007/s10556-017-0349-z

[24] Monn, J.A., Raffio, T.S., Kissock, K. (2012). Energy efficient mechanical press and hydraulic system operation. SAE Technical Paper. https://doi.org/10.4271/2012-01-0326

[25] Kramer, M., Rexroth, B. (2020). General extrusions implements press hydraulics upgrade with phased approach. Light Metal Age, 78(3): 36-39. 